\title{
Fasciola hepatica tanısında endosonografinin rolü
}

\section{Role of endosonography in Fasciola hepatica}

Hacı Mehmet ODABAŞI, Mehmet Kamil YILDIZ, Cengiz ERIŞ, Hacı Hasan ABUOĞLU, Emre GÜNAY, Erkan ÖZKAN, Tolga MÜFTÜOĞLU

Haydarpaşa Numune Eğitim ve Araştırma Hastanesi Genel Cerrahi Kliniği, Istanbul

Fasciola hepatica, tüm dünyada koyun, keçi, sığır, manda, at ve tavşan gibi otçul hayvanlarda yaygın olarak görülen yaprak şeklinde bir parazittir. Zaman zaman insanları da etkiler. Nonendemik bölgelerde nadir görülmesi sebebiyle hastalığın teşhisinde zorluklar ve gecikmeler yaşanılmaktadır. Konvansiyonel görüntüleme yöntemleri ile tanı koymak oldukça güçtür, tanı genellikle endoskopik retrograd kolanjiopankreotografi ile konulmaktadır. Endosonografi safra yolu hastalıklarının teşhisinde yeni ve önemli bir tanı yöntemi olarak yerini almıştır. Biz endosonografi ile tanısı konulan ve endoskopik retrograd kolanjiopankreatografi ile tedavi edilen olgumuzu sunuyoruz.

Anahtar Kelimeler: Fasciola hepatica, endosonografi, ERKP

\section{GİRIŞ}

Fasciola hepatica tüm dünyada koyun, keçi, sığır, manda, at ve tavşan gibi otçul hayvanlarda yaygın olarak görülen, insanlarda sporadik olarak rastlanılan, tatlı su salyangozlarının arakonakçı olduğu yaprak şeklinde bir parazittir (1). İnsanlarda enfeksiyon daha çok koyun yetiştirilen bölgelerde su teresi veya suda yetişen bitkilerin tüketilmesi ile gelişmektedir (2-4). Özellikle nonendemik bölgelerde tanı koymak oldukça güçtür.

Endosonografi (EUS) safra yolu hastalıklarının teşhisinde yeni ve önemli bir tanı yöntemi olarak yerini almıştır. Biz endosonografi ile tanısı konulan ve endoskopik retrograd kolanjiopankreatografi (ERKP) ile tedavi edilen olgumuzu literatür eşliğinde sunuyoruz.

\section{OLGU SUNUMU}

Kırküç yaşında kadın hasta sağ üst kadran ağrısı, sarılık ve ateş şikayeti ile acil polikliniğimize başvurdu. Kolanjit tanısı ile yatırılan hastanın tüm batın ultrasonografisinde safra kesesinin lojunda izlenmediği, koledok çapı $11 \mathrm{~mm}$ ile artmış olup koledok distalinde milimetrik boyutlu birkaç adet kalkül ile uyumlu ekojenite rapor edildi ve hastaya manyetik rezonans kolanjiopankreotografi (MRKP) yapılması önerildi.
Fasciola hepatica, a leaf-like parasite, has a worldwide distribution in a large variety of grass-grazing animals such as sheep, goats, cattle, buffaloes, horses, and rabbits. Fascioliasis may affect man occasionally. Because of the rarity in nonendemic regions, difficulties and delays are experienced in the diagnosis of the disease. It is very difficult to diagnose with conventional imaging methods, and diagnosis is usually made by endoscopic retrograde cholangiopancreatography. Endosonography in the diagnosis of biliary tract diseases has taken its place as a novel and important diagnostic method. We present an endosonographically diagnosed case that was treated with endoscopic retrograde cholangiopancreatography.

Key words: Fasciola hepatica, endosonography, endoscopic retrograde cholangiopancreatography, ERCP

Hastanın MRKP'sinde intrahepatik safra yolları hafif belirgin, ana safra kanalı $8 \mathrm{~mm}$ ve koledok $10 \mathrm{~mm}$ idi. Koledok distal uçta papilla lokalizasyonunda, belirgin bir kalkül ile uyumlu sinyal özellikleri taşımamakla birlikte tümefaktif çamur ile uyumlu olabilecek milimetrik boyutlarda yapı (çamur ?) şeklinde rapor edildi.

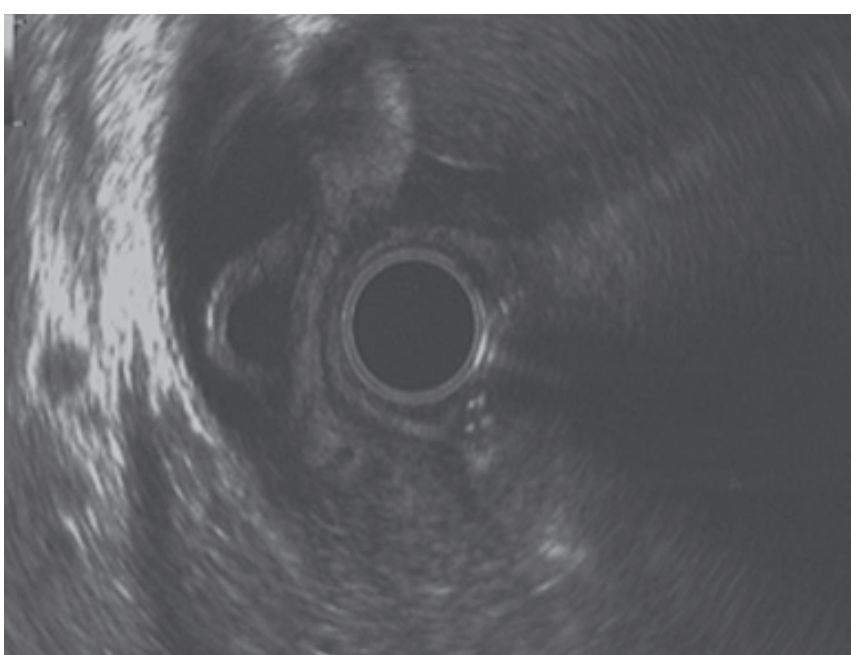

Resim 1. Fasciola hepatica'nın endosonografik görünümü. 


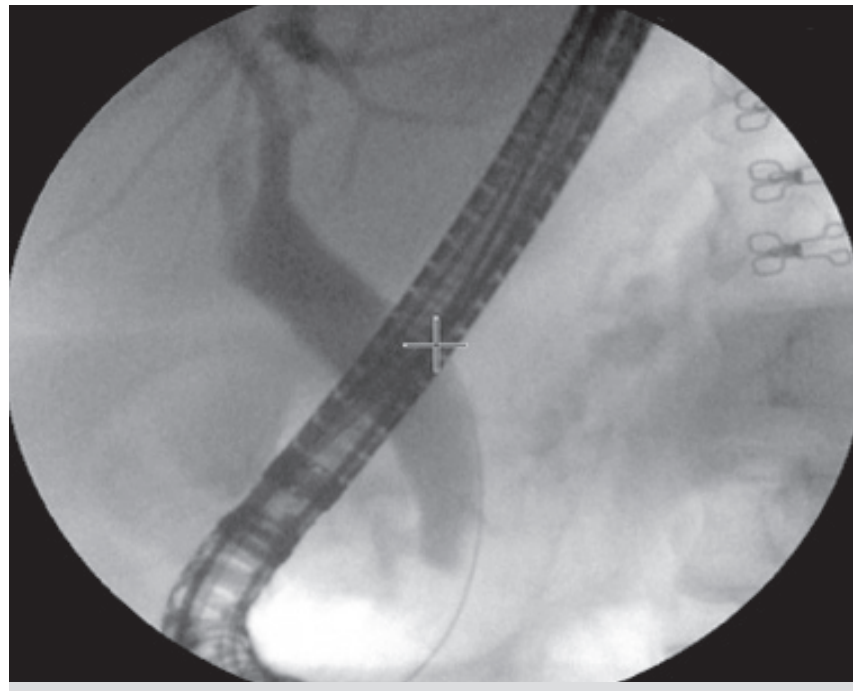

Resim 2. Fasciola hepatica ERKP'de koledok alt uçta dolum defekti şeklinde gözükmekteydi.

Hastanın laboratuvar testleri ise AST: 174 U/L, ALT: 338 U/L, GGT: 232 U/L, ALP: 361 U/L, T.bil: 8,85 mg/dl, D.

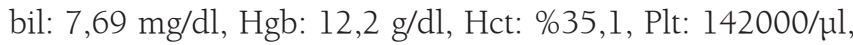
WBC: 5040/ $\mu$ l, Eozinofil: \%3.6, Amilaz 117 U/L idi. Hastaya olası koledok alt ucu malignitesini ekarte etmek amaciyla endosonografi yapildı. Endosonografisinde koledok $12 \mathrm{~mm}$, pankreas kanalı $4 \mathrm{~mm}$ idi. Koledok içerisinde hareketli yaprak şeklinde paraziter bir yapı, muhtemelen Fasciola hepatica olarak rapor edildi (Resim 1). ERKP yapıldı. ERKP'de papilla düzgün ama ödemli görünümde idi. Koledok ve intrahepatik safra yolları hafif dilate izlendi. Koledok kanüle edildi ve alt uçta Fasciola hepatica olduğu düşünülen yarım ay şeklinde negatif yapının koledok distalini kapattığı görüldü (Resim 2). Sfinkterotomi tamamlanarak koledok balonla sıvazlandığında bir adet canlı Fasciola hepatica geldiği görüldü (Resim 3).

ERKP sonrasi $10 \mathrm{mg} / \mathrm{kg}(750 \mathrm{mg}) 2 \mathrm{doz}$ şeklinde triclabendazole tedavisi başlandı ve kısa sürede biyokimyasal değerler normale döndü. Kontrol ultrasonografisinde safra yolları tamamen normale dönmüştü.

\section{TARTIŞMA}

Fasciola hepatica genellikle insanlara koyunların yoğun olarak yaşadığı kırsal bölgelerde enfekte olmuş su teresi veya suda yetişen bitkilerin tüketilmesi ile bulaşmaktadır. Hastalık sadece enfekte gıdaların alınması ile gelişmez; enfekte suyun içilmesi, çiğ ya da az pişirilmiş hastalıklı hayvanların karaciğerinin yenilmesi, iyi yıkanmamıs marul veya ıspanak ile de bulaşabilmektedir. Bu nedenle kırsal kesimle sınırlı olmayıp gelişmiş şehirlerde de görülmektedir $(5,6)$.

Dünya üzerinde 2,4 milyon Fascioliasis ile enfekte insan ve 180 milyon risk altında kişi düşünülmektedir. Bu zoonotik

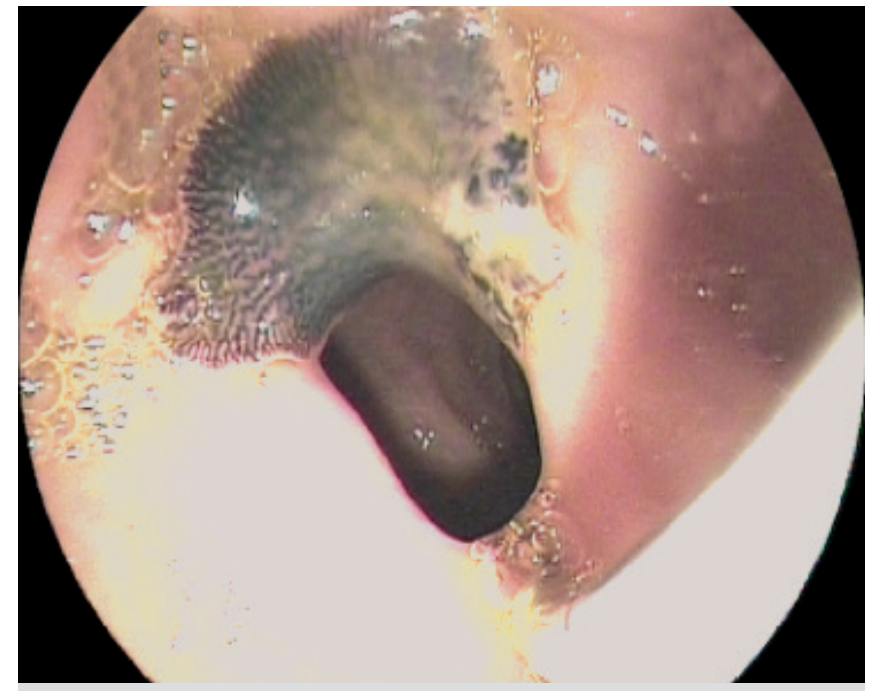

Resim 3. ERKP'de balonla koledoktan duodenuma çıkartılan canlı Fasciola hepatica.

enfeksiyon Afrika, Batı Avrupa ve Latin Amerika'da sık gözlenmektedir $(2,7)$. Türkiye'nin doğusundan bildirilen bir yayında seroprevelans \%2,78 olarak bulunmuştur (8).

Metacercaria denilen formu ağızdan alındıktan sonra duodenumda larvaya dönüşür. Larvalar ince barsak duvarını delerek peritona geçer, daha sonra karaciğer kapsülünü penetre eder ve karaciğer parankiminde ilerleyerek safra kanallarına ulaşırlar. Bu durum sadece bir kaç gün içerisinde gelişir. Larva bir kaç hafta karaciğer içerisinde kalır, karaciğer parankiminde nekroz ve fibrozise neden olur, daha sonra son halini almak için safra yollarına geçer ve erişkin halini alır. Erişkin Fasciola hepatica yaklassık $3 \mathrm{~cm}$ uzunluğunda ve $1 \mathrm{~cm}$ genişliğinde ve yaprak şeklindedir. Metacercaria safhasından erişkin hale gelmesi yaklaşık 3 ay kadar sürmektedir. Bu nedenle ilk 3 ay içerisinde tanı konulması güçtür. Hastalığın iki aşaması mevcuttur: Akut dönem larvaların karaciğer içine göç ettiği ve konakladığı dönemdir. Sağ üst kadran ağrısı, ateş ve hepatomegali görülür. Ayrıca iştahsızlık, bulantı, kusma, myalji ve ürtiker görülebilir. Belirgin periferik eozinofili görülür. Ancak bu bulgular nonspesifik olduğundan teşhisi kolay değildir. Kronik dönemde ise, semptomlar kaybolur. Genellikle asemptomatik olmakla birlikte erişkin Fasciola hepatica safra kanalını tıkayarak tıkanma sarılığı ve kolanjite neden olabilir $(3,7)$.

Bizim hastamızda safra yollarında genişleme ve kolanjit bulguları vardı. Yapılan tetkiklerinde eozinofili saptanmadı. Olgumuzda literatürde bildirilen vakaların $(9,10)$ aksine eozinofili yoktu. Bu da kronik fazda eozinofilinin tanıda yardımcı olmayabileceğini göstermektedir.

Tanı genellikle gaita, duodenal aspirat veya safra sıvisında yumurta gösterilmesi ile konur. Ayrıca safra yolu obstrüksiyonu için yapılan cerrahi veya endoskopide erişkin Fasciola hepa- 
tica görülebilir. Akut fazda gaitada yumurta görülemez. Bu safhada hastanın kliniği ve periferik eozinofili ile tanı konur. Bilgisayarlı tomografi (BT)'lerde hipodens tünel benzeri dallanan lezyonlar görülebilir. Serolojik testlerle tanı konabilir. Bu testlerin duyarlılıkları yüksek ancak özgünlükleri düşüktür ve diğer paraziter enfeksiyonlarla çapraz reaksiyon verebilirler. Enfeksiyondan yıllar sonra bile serolojik testlerin titreleri düşmekle birlikte pozitif kalabilir. Biliyer fazda endosonografi veya ERKP ile Fasciola hepatica görülebilir. Bizim hastamız da endosonografi ve nihayetinde ERKP ile canlı yassı solucanin gösterilmesi ile tanı aldı. Karaciğer biyopsisinde nadiren Fasciola yumurtaları görülür. Fasciola hepatica enfestasyonu ülkemizin özellikle Doğu ve Güneydoğu bölgelerinden gelen ve su kenarında yetişen bitki tüketimi bulunan hastalarda akut veya kronik faza ait bulgularla karşımıza gelebilir. Akut fazda klinik tablo, periferik eozinofili ve gerekirse serolojik testlerle tanı konabilirken kronik fazda hasta kolanjit, obstrüktif sarılık gibi safrayolu taşı veya malignitesi düşündüren klinikle karşımıza gelebilir. Bu fazda periferik eozinofili görülmeyebileceği için uygun hastalarda bu tanı akılda tutulmalı ve görüntüleme yöntemleri bu açıdan da değerlendirilmelidir (11).

Fasciola enfestasyonlarinda semptomlarin ve laboratuvar değerlerinin spesifik olmaması, büyük şehirlerde nadir görülmesi ve çok sayıda vaka olmaması veya sayıdaki artışın farkında olunmaması nedeniyle, hekimler birçok teşhis yöntemini uygulayarak zaman kaybına neden olmaktadırlar (12).

EUS, kolanjiyografi ve ERKP enfestasyonun biliyer safhasında biliyer ağacı değerlendirmede daha yararlıdır ve hareketli parazitleri gösterebilirler (13-15). EUS'un MRKP gibi bir noninvaziv yöntem olarak mükemmel bir doğruluğa sahip olduğu vurgulanmalıdır. Aynı şekilde, National Institutes of Health (NIH) konsensus toplantisinda ERKP'nin sadece koledokolityazis olasılığının yüksek olduğu klinik durumlarda kullanılması tavsiye edilmiştir. Sadece koledokolityazis tanısı için, EUS ve MRKP'nin doğrulukta ERKP'ye benzer olduğu belirtilmiştir (16).

\section{REFERANSLAR}

1. Haseeb AN, el-Shazly AM, Arafa MA, Morsy AT. A review on fascioliasis in Egypt. J Egypt Soc Parasitol 2002; 32:317-54.

2. Mas-Coma, S. Epidemiology of fascioliasis in human endemic areas. J Helminthol 2005; 79:207-16

3. Gulsen MT, Savas MC, Koruk M, et al. Fascioliasis: a report of five cases presenting with common bile duct obstruction. Neth J Med 2006; 64:17-9.

4. Bahçecioğlu IH, Yalniz M, Ataseven H, et al. Biliary fasciolosis: a report of three cases diagnosed by ERCP. Turkiye Parazitol Derg 2008; 32:3758. (Turkish).

5. Rondelaud D, Hourdin P, Vignoles P, Dreyfuss G. The contamination of wild watercress with Fasciola hepatica in central France depends on the ability of several lymnaeid snails to migrate upstream towards the beds. Parasitol Res 2005; 95:305-9.
Abdominal sonografi ve BT gibi görüntüleme çalışmaları tümör için tanıda benzer şekilde yanıltıcı olabilirler. EUS lezyonu net olarak tanımlamıştır ve ERKP yapılmasını önermiştir. Fasciola hepatica başarılı bir sfinkterotomi sonrası safra yolundan çıkartılmış ve duodenuma düşürülmüştür.

Fasciola hepatica zaman içerisinde periduktal fibrosis ve duvar kalınlaşmasına dolayısıyla tıkanmaya neden olabilir. Bu nedenle ultrasonografi ve bilgisayarl tomografide (BT) malignite veya taş ile karıştırılabilir (17). Hastalık teşhisinde ultrasonografi kesin bilgi veremeyebilir ve BT ultrasonografiden daha üstün değildir. En yararlı yöntemler ERKP ve son olarak MRKP'dir. Ultrasonografi, BT ve MRKP'deki bazı teknik kısıtlilıklar nedeniyle ERKP bu görüntüleme yöntemlerinden üstündür. Bu nedenle ERKP safra yolu görüntülenmesinde altın standart olarak düşünülmektedir $(18,19)$.

Aynı şekilde, kronik dönemde tanı ultrasonografi ya da BT ile konulmuş olsa bile, bu hastalarda ERKP ilk seçenek düşünülmelidir (10). Ancak, radyolojik özellikleri ile tanımlanabilen kronik Fascioliasis vaka sayısı azdır (17).

Hastalığın akut döneminde sadece ilaçlarla yeterli tedavi sağlanırken, kronik dönemde ilaç tedavisine bağlı ölü parazitlerin safra yolu tıkanıklığına yol açma riski nedeniyle safra yollarının endoskopik mekanik temizliği gerekmektedir. Fascioliasis nedeniyle safra tıkanıklığı olduğunda, ERKP ve sfinkterotomi ile parazitler başarılı ve güvenli bir şekilde kullanılmaktadır $(21,22)$.

Biz hastamızı ERKP ve sfinkterotomi sonrası, triclabendazole ile tedavi ettik ve 1 ylllk takibimizde herhangi bir nüks ile karşılaşmadık.

Sonuç olarak, tüm dünyada Fasciola hepatica enfestasyonu artmaktadır, hastaların seyahat veya göç gibi öyküleri bilinmeli ve hastalıktan haberdar olmalıdırlar. ERKP halen tanı ve tedavideki önemini korumaktadır, ancak hastaların zaman kaybını engellemek için BT veya MRKP den önce, hastaların EUS ile değerlendirilmesi daha uygun olacaktır.

6. Marcos L, Maco V, Samalvides F, et al. Risk factors for Fasciola hepatica infection in children: a case- control study. Trans R Soc Trop Med Hyg 2006; 100:158-66

7. Haseeb AN, El-Shazly AM, Arafa MA, Morsy AT,. Clinical, laboratory and ultrasonography features of proven human fascioliasis. J Egypt Soc Parasitol 2003; 33:397-412.

8. Kaplan M, Kuk S, Kalkan A, et al. Fasciola hepatica seroprevalence in the Elazig region. Mikrobiyol Bul 2002; 36:337-42.

9. Adachi S, Kotani K, Shimizu T, et al. Asymptomatic fascioliasis. Intern Med 2005; 44:1013-5.

10. Harinasuta T, Bunnag D, 1990. Liver, lung and intestinal tremato-diasis. In: Warren KS, Mahmoud AF, (eds.) Tropical and Geographical Diseases. 2nd ed. New York: McGraw-Hill, p.473-489. 
11. Tayfur Ö, Metin O, Dişibeyaz S, et al. Oddi tümörünü taklit eden bir biliyer fascioliasis olgusu. Endoskopi 2009; 17:119-21.

12. Graham CS, Brodie SB, Weller PF. Imported Fasciola hepatica infection in the United States and treatment with triclabendazole. Cin Infect Dis 2001; 33:1- 5 .

13. Sezgin O, Altintas E, Disibeyaz S, et al. Hepatobiliary fascioliasis: clinical and radiologic features and endoscopic management. J Clin Gastroenterol 2004; 38:285-91.

14. Aubert A, Meduri B, Prat F, et al. Fascioliasis of the common bile duct: endoscopic ultrasonographic diagnosis and endoscopic sphincterotomy. Gastroenterol Clin Biol 2001; 25:703-6.

15. Sotoudehmanesh R, Yoonessi A. Diagnosis of Fasciola hepatica by endoscopic ultrasound. Endoscopy 2003; 35:1088.

16. Wang DQH, Afdhal NH. Gallstone disease; in Feldman M, Friedman LS, Brandt LJ (eds): Sleisenger and Fordtran's Gastrointestinal and Liver Disease, ed 9. New York, Saunders, 2010, pp 1110-1.
17. Dias LM, Silva R, Viana HL, et al. Biliary fascioliasis: diagnosis, treatment and follow-up by ERCP. Gastrointest Endosc 1996; 43:616-20.

18. Suhocki PV. Percutaneous Transhepatic cholangiography (PTC). In: Johnson LR (editor). Encyclopedia of Gastroenterology. San Diego, California: Elsevier, 2004: 154-9.

19. Osman M, Lausten SB, El-Sefi T, et al. Biliary parasites. Dig Surg 1998; 15:287-96.

20. Dowidar N, Sayad ME, Osman M, Salem A. Endoscopic therapy of $f$ ascioliasis resist ant to oral therapy. Gastrointest Endosc 1999; 50:34551.

21. Condomines J, Rene-Espinet JM, Espinos-Perez JC, Vilardell F. Percutaneous cholangiography in the diagnosis of hepatic fascioliasis. Am J Gastroenterol 1985: 80:384-6.

22. Veerappan A, Siegel JH, Podany J, et al. Fasciola hepatica pancreatitis: endoscopic extraction of live parasites. Gastrointest Endosc 1991; $37: 473-5$ 